\title{
Training for competitiveness
}

from Richard Pearson

"The same machines and equipment can be bought by anybody; success in the market goes to those
who have a workforce that can use them to best advantage."

INVESTMENT in people is being seen as the key to economic success once again. The 1960 s saw the growing acceptance of the concept of 'human capital' and 'human asset accounting', and in the United Kingdom legislation set up an infrastructure to stimulate and manage training, and to redistribute its costs between the trainers through the Industrial Training Boards. By the late 1970s little progress had been made, the bureaucracies were seen to have taken over, and the incoming Conservative government enacted legislation which led to the demise of most of the training boards. In the mid-1980s training is back in vogue and the publication of Competance and Competition (HMSO, 1984; see Nature 313,$82 ; 1985$ ) was part of a new campaign to boost training in the United Kingdom. It highlighted the United Kingdom's 'poor' training performance relative to West Germany, Japan and the US countries where individuals, employers and the state all placed greater value on training, seeing it as necessary capital investment, rather than as a cost.

A survey of UK employers in 1984 showed that while 90 per cent of managers recognized the importance of training, only one in three adults had received any training in the previous year. Privatesector establishments were estimated to have spent over $£ 2,000$ million on training adults that year, which averaged $£ 200$ per employee or $£ 575$ per trainee. Two-thirds of the training was done on-the-job, the rest through courses, with 4 per cent via evening classes and distance learning (Fig. 1).

While the link between training and a company's performance is hard to prove, it was shown that high-performance businesses, defined as those that were profitable, growing and innovating, were twice as likely to be training their staff as were low performers. They also trained twice as many staff and had increased their volume of training by over 25 per cent in the previous five years. By contrast, the low performers had cut their training by as much as 20 per cent over the same period.

The most recent major report in support of the national training campaign is $A$ Challenge to Complacency: Changing Attitudes to Training (MSC/NEDO, 1985) which sought to identify the 'why' of our low training performance and hence the scope for encouraging companies to increase their investment in training. The report makes depressing reading. It shows employers' lack of concern about training and highlights the widespread ignorance among top management as to the scale of resources their organization devoted to training. Decisions about training were predominantly taken by line managers who inevitably focused on short-term needs. In technical areas this is often manifest as a willingness to send people to conferences or short courses to pick up the latest technology, but a neglect or lack of

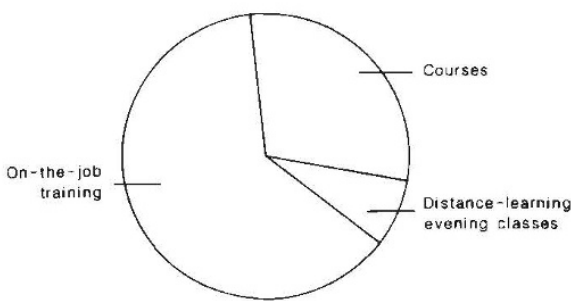

Fig. 1 Types of training. On-the-job training, courses and distance-learning/evening courses annually occupy 34 million, 17 million and 2 million days respectively. (Source: IMS)

interest in the longer-term development of staff. Little attention is paid to the analysis of training needs or evaluation of its results, and training managers and departments have relatively low status. Training is seen as a cost and overhead, to be cut when profits are under pressure, rather than as an investment in the future. In Britain, training was cut in the recession, while in West Germany and Japan the pressure was to increase the level of training given. As the remark made by a West German employer and shown in the introduction reveals, other countries are well aware that competitive advantage can only come through attuning people to a technological world.

The reluctance to invest in training was put down to uncertainties about future prospects and technological change, worries about 'poaching' by other employers and poor experiences with some external trainers. High trainee wage costs were not seen as a problem. At the same time there was little pressure from individual employees or unions, external commentators and investors, or from the government to do better, although the picture is beginning to change.

A number of proposals have been put forward to improve matters. For employers, the preparation and dissemination of case studies showing the links between training and performance are seen to be important. Employers should also be en- couraged to report regularly on their training. This will require the development of training indicators, initially focusing on inputs such as man days, money invested (not cost!), type of training, whether it be on-the-job or off-the-job, training staff employed and so on. The process of collecting such data would be a major innovation for many companies and is likely immediately to raise the general awareness of training. In the longer term, indicators of training output or performance need to be developed but this will take some time. Individual employees can be an important stimulus for more training; in the United States, for example, it is notable the extent to which individuals seek out and invest in training. In the United Kingdom it is suggested that Individual Training Credits (ITCs) to which individuals and employers contribute, as for occupational pensions, should be set up to pay for approved training. The ITCs would need to be transferable so that they could be stored and used to retrain between jobs for example, and could also be used to incorporate grants to individuals, for example at the start of working life or following redundancy. They could also help share the costs of training more equitably and reduce the fears of losses due to poaching. Of course, if training was at a much higher level overall, there would be less poaching in the first place.

The report also argues the need to improve the operation of the training market, for example by helping colleges to become more responsive to market needs, and to improve the working of local labour markets and collaborative training arrangements. Another need is for better information on training availability; at present, many training specialists are confused at the wide variety of training on offer and find it difficult to choose the most relevant and effective course. While registers and databases help as to availability, ideally more qualitative assessments are also needed. Many other mechanisms such as grants and fiscal measures are also reviewed in the report.

The analyses of the need to train are getting more frequent, hopefully raising the awareness of its value to employee and employer alike. Time will tell if this is translated into an analysis of training needs which is then acted upon.

Richard Pearson is at the Institute of Manpower Studies, Mantell Buildings, University of Sussex, Brighton BN1 9RF, UK. 